\title{
Maximum entropy modeling for the conservation of Hopea odorata in riparian forests, central Thailand
}

\author{
LAMTHAI ASANOK ${ }^{1}$, TORLARP KAMYO ${ }^{1, \boldsymbol{v}}$, DOKRAK MAROD ${ }^{2}$ \\ ${ }^{1}$ Department of Agroforestry, Maejo University. Phrae Campus, Phrae 54140, Thailand. Tel./fax.: +66-546-48374, `email: torlarp66@ gmail.com. \\ ${ }^{2}$ Department of Forest Biology, Faculty of Forestry, Kasetsart University. 50 Phahonyothin Rd, Lat Yao, Chatuchak, Bangkok 10900, Thailand
}

Manuscript received: 1 July 2020. Revision accepted: 19 September 2020.

\begin{abstract}
Asanok L, Kamyo T, Marod D. 2020. Maximum entropy modeling for the conservation of Hopea odorata in riparian forests, central Thailand. Biodiversitas 21: 4663-4670. Hopea odorata plays a dominant role in both ecologically and economically in Thailand. We analyzed potentially suitable areas for $H$. odorata in the riparian zone of the Chao Phraya River using the software MaxEnt. Modeling included 164 occurrence records along with 19 climate-related variables, slope, aspect, and elevation. Precipitation was the key climatic variable influencing the distribution of $H$. odorata. Riparian areas along the Chao Phraya that were predicted to be highly suitable for this species were located in the provinces of Nakhon Sawan, Ang Thong, Phra Nakhon Si Ayutthaya, Pathum Thani, Nonthaburi, and Bangkok. The ROC AUC score was 0.891, indicating that MaxEnt is an excellent tool for predicting suitable regions for the restoration or cultivation of commercially and ecologically valuable species such as $H$. odorata. Models such as what we have presented here can facilitate habitat conservation and sustainable resource use for rare and important plants.
\end{abstract}

Keywords: Dipterocarpaceae, ecological niche, habitat suitability, native species conservation, predictive modeling

\section{INTRODUCTION}

The most pressing task for forest researchers and managers today is to conduct quantitative assessments of deforestation and afforestation and apply the obtained results to tackle issues related to forest change. Native tree species are suitable for reclaiming degraded lands as well as for timber production (Montagnini and Jordan 2005; Sakai et al. 2009; Lamb 2010; Zimmer et al. 2018). Hopea odorata Roxb. (Dipterocarpaceae) is an important timber tree that plays an outsized role in the ecology and economics of riparian forests in Thailand (Orwa et al. 2009; Asanok et al. 2017). H. odorata's timber is a strong, light hardwood that is used for both heavy and light construction, furniture, veneer, and other applications. In terms of other uses, the bark has a high tannin content and therefore is suitable for tanning leather (Hossain et al. 2015). H. odorata is an evergreen, late-successional tree species that require shade and a high soil moisture content for natural regeneration. It is suitable for reclamation planting and is also widely planted as an ornamental and shade tree (Bunyavejchewin et al. 2003; Sakai et al. 2009; Ashton and Kaettle 2012). The species is restricted to tropical forests in Myanmar, Thailand, Laos, Vietnam, and northern Peninsular Malaysia (Bunyavejchewin et al. 2003; Satiraphan et al. 2012). Typical habitats include low-relief areas or riparian forests on deep, rich soils, often along the banks of streams, and wet areas up to $600 \mathrm{~m}$ in elevation. It reaches optimal growth is reached in areas with $>1,200$ $\mathrm{mm}$ of annual precipitation and a mean annual temperature of $25-27^{\circ} \mathrm{C}$ (Narong and Sobon 2014).
The Chao Phraya River lies at the center of Thai economic and social development region, running through 11 cities along its $372 \mathrm{~km}$ length. H. odorata is the dominant species within the river's riparian areas. However, disturbance associated with urbanization and agriculture has frequently degraded these riparian forests and local and regional land-use changes have been linked to declines in H. odorata populations (Asanok et al. 2017). Ecological modeling can be used to estimate the distribution of $H$. odorata in Thailand, and perhaps more critically, can provide insight into the environmental factors affecting its distribution. In this study, we analyzed habitat and environmental data with an aim to better conserve and manage riparian forests along the Chao Phraya River.

Techniques including statistical modeling and geographic information systems (GIS) have been widely applied in ecology for conservation and resource management (Guisan and Zimmermann 2000; Warren et al. 2008; Brito et al. 2009; Abdelaal et al. 2019). In particular, species distribution models (SDMs) exploit the associations between site-level species occurrences and the environmental features of those locations to make predictions in space and/or time (Franklin 2009; Fois et al. 2016; Amici et al. 2017; Fois et al. 2016; Safaei et al. 2018; Abdelaal et al. 2019). For the purpose, species Occurrence records are obtained through field surveys as well as from herbarium and museum databases. Maximum entropy (MaxEnt) is a relatively standard model machine learning protocol for predicting species distributions. It has been widely used to predict suitable areas for endangered species, assesses climatic suitability for species, and 
provide priority assessments for conservation (Zheng et al. 2016; Koch et al. 2017). It is a niche modeling framework that generalizes specific observations of species presence and does not require absence points. Its key advantages are that it only requires presence data, which are often more widely available, can accept both continuous and categorical data, and employs efficient deterministic algorithms. Furthermore, the output is continuous and generative and the model is suitable for small sample sizes.

Despite advancements in plantation management, $H$. odorata is considered a threatened species with a reduced, degraded natural distribution. Therefore, we focused on $H$. odorata as a representative of the broader issues of conservation and sustainable use of riparian plants along the Chao Phraya River. Our objectives were to characterize the habitat and niche of $H$. odorata based on field observations, identify landscape-scale environmental correlates through niche-based models, and identify suitable areas for $H$. odorata conservation.

\section{MATERIALS AND METHODS}

\section{Study area and species occurrence data}

The study area was located in the floodplain of the riparian zone of the Chao Phraya River, which begins in the Pak Nam Pho sector of Nakhon Sawan Province and ends in the Pak Nam sector of Samut Prakan Province (Figure 1). The Chao Phraya River is the main river in central Thailand and its origin, in Nakhon Sawan Province, is quite far from the ocean, whereas the mouth, located in Samut Prakan Province, forms an estuary along the coast of the Gulf of Thailand. We focused on the floodplain, here meaning the area between the water's edge and the highwater mark. We used the highest watermark recorded from flooding in 2011 as a cutoff, which was between 0-30 $\mathrm{m}$ in elevation depending on the area (Hydro and Agro Informatics Institute, 2012; Gale and Saunders 2014). The resulting study area was $14,252 \mathrm{~km}^{2}$ in size (Figure 1)

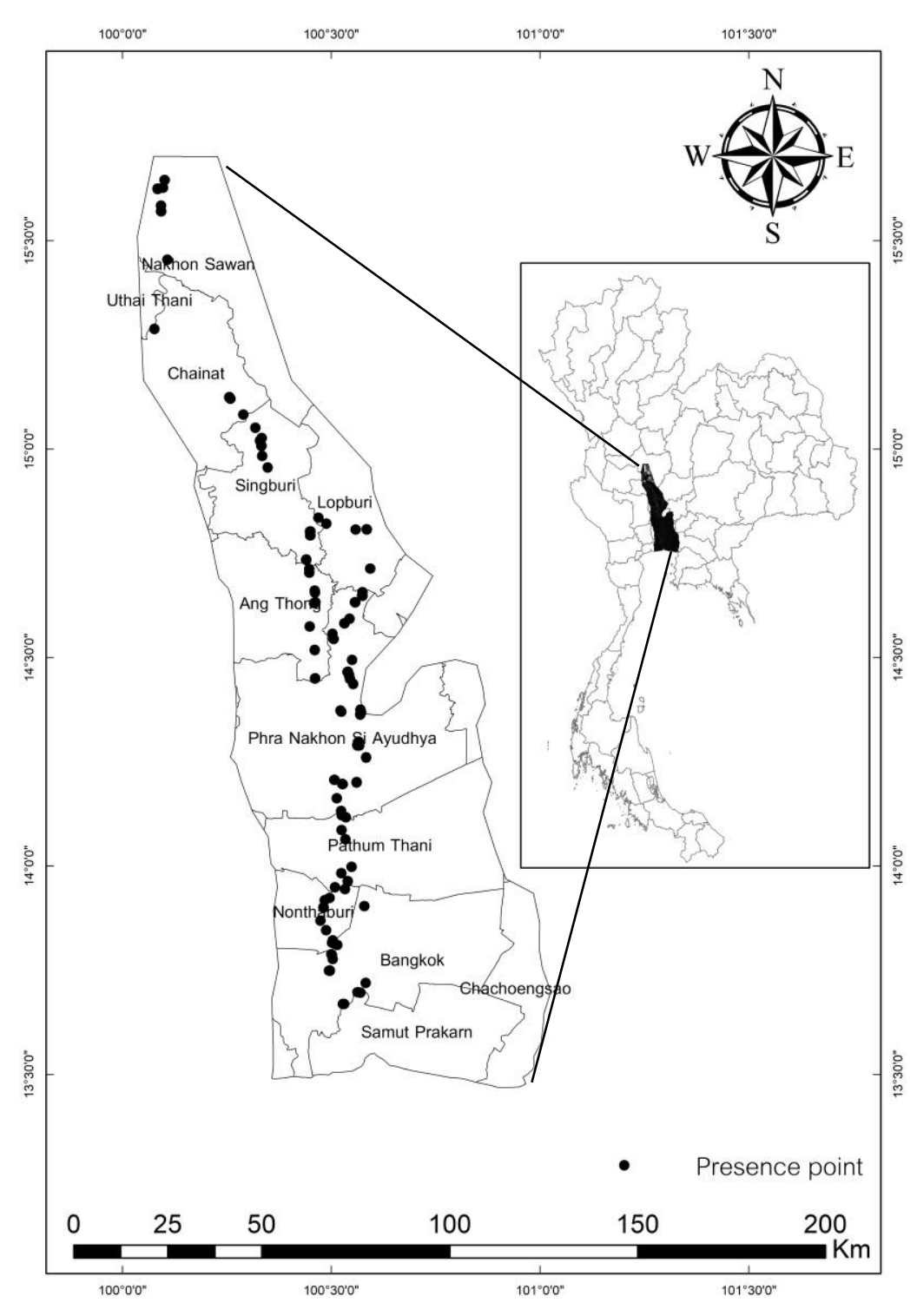

Figure 1. Study area and locations of Hopea odorata populations $(n=164)$ recorded during randomized field surveys 
Table 1. Nineteen candidate bioclimatic factors obtained from WorldClim for use in MaxEnt models

\begin{tabular}{|c|c|}
\hline Code & Parameter \\
\hline BIO1 & Mean annual temperature \\
\hline $\mathrm{BIO}^{*}$ & $\begin{array}{l}\text { Mean diurnal range )the mean monthly difference } \\
\text { between maximum and minimum temperature( }\end{array}$ \\
\hline $\mathrm{BIO}^{*}$ & Isothermality $)) \mathrm{BIO} 2 / \mathrm{BIO} 7(\times 100($ \\
\hline $\mathrm{BIO}^{*}$ & Temperature seasonality )standard deviation $\times 100($ \\
\hline $\mathrm{BIO}^{*}$ & Maximum temperature in the warmest month \\
\hline $\mathrm{BIO}^{*}$ & Minimum temperature in the coldest month \\
\hline $\mathrm{BIO}^{*}$ & Annual temperature range )BIO5-BIO6( \\
\hline $\mathrm{BIO} 8$ & Mean temperature of the wettest quarter \\
\hline BIO9 & Mean temperature of the driest quarter \\
\hline BIO10* & Mean temperature of the warmest quarter \\
\hline $\mathrm{BIO} 11^{*}$ & Mean temperature of the coldest quarter \\
\hline $\mathrm{BIO} 12^{*}$ & Annual precipitation \\
\hline $\mathrm{BIO}^{*}$ & Precipitation in the wettest month \\
\hline $\mathrm{BIO} 14$ & Precipitation in the driest month \\
\hline $\mathrm{BIO} 15$ & Precipitation seasonality )coefficient of variation( \\
\hline $\mathrm{BIO}^{*}$ & Precipitation in the wettest quarter \\
\hline BIO17 & Precipitation in the driest quarter \\
\hline BIO18 & Precipitation in the warmest quarter \\
\hline BIO19* & Precipitation in the coldest quarter \\
\hline
\end{tabular}

Hopea odorata locations were obtained using randomized field surveys in the study area. The field study period was from January 2018 to December 2018. Oldgrowth riverine forests along the Chao Phraya River were selected for study. Plant samples were collected and herbarium specimens were prepared and submitted to the Forest Herbarium at the Department of National Parks, Wildlife and Plant Conservation, Bangkok, for identification and validation. A total of 164 sites with populations of $H$. odorata were identified (Figure 1) and their geographical coordinates were recorded using a Garmin GPS 76 handset (Jaryan et al. 2013).

\section{Modeling procedure}

Species location data were appropriately formatted as inputs for MaxEnt. In addition to occurrence data, environmental parameters are necessary for MaxEnt modeling. We used 19 bioclimatic parameters available from WorldClim-Global Climate Data version 2.0 (WorldClim, https://www.worldclim.org/data/bioclim.html) for the study area. These variables represented annual and seasonal trends, including mean temperature of the warmest and coldest quarters, annual precipitation, and annual temperature range, as well as limiting environmental factors such as the temperature of the coldest and hottest months (Table 1). Data were available at a 30 arc-second resolution and were obtained in GRID format (Hijmans et al. 2005). All files were converted into ASCII format using Arc GIS version 10.6 (Scheldeman and Zonneveld 2010; Kamyo and Asanok 2020) for use in MaxEnt. Given that a species ecological niche is invariably greater than its geographical range, a supported approach is to use a maximum amount of information when modeling species distributions and determining variables directly linked to distribution. In addition, we performed ground validation during field surveys.

Prior to modeling, we checked for correlations among the predictor variables, as highly correlated input variables are a known source of error in spatial models (Dormann et al. 2007), in $\mathrm{R}$ version 3.4.1 ( $\mathrm{R}$ Core Development Team). We used a correlation coefficient cutoff of 0.9. Based on the resulting correlation coefficients, knowledge of the species' ecology, and relevant environmental factors, we selected 12 WorldClim variables, as well as aspect, slope, and elevation (from the Shuttle Radar Topography Mission Digital Elevation Model; http://srtm.usgs.gov/index.php), for use in MaxEnt models.

We used MaxEnt version 3.4.1, available from http://biodiversityinformatics.amnh.org/opensource/maxent, for analyses. The MaxEnt output is a continuous prediction of habitat suitability for a given species from 0 (lowest suitability) to 1 (maximum suitability) (Elith et al. 2010; Zhu et al. 2017). The model also generates response curves for each predictor variable and uses the jackknife method to estimate the relative influence of each predictor variable (Fielding and Bell 2007; Khanum et al. 2013; Swanti et al. 2018). The environmental variables and the species occurrence data $H$. odorata were loaded into the MaxEnt model; $75 \%$ of the location data were used for training, and the remaining $25 \%$ were used to test the predictive ability of the model. The model ran either 1000 iterations of this processesor continued until a convergence threshold of 0.00001 was met. We evaluated model performance using the omission-commission rate, a threshold-dependent binomial test based on omissions and predicted area (Phillips and Dudk 2008). The omission rate is the proportion of test localities that fall into pixels not predicted as suitable, and the predicted area is the proportion of all pixels that are predicted to be ideal (Phillips et al. 2006; Elith et al. 2011). We also used threshold-independent receiver operating characteristic (ROC) curves and area under the ROC curve (AUC) for model evaluation, where AUC is a measure of model performance. An ROC curve plots sensitivity (true positives) and fall-out (false positives). Here, fall-out was defined as 1- specificity and specificity were defined as the predicted area. Four arbitrary categories of habitat suitability were defined, based on the predicted habitat suitability results for $H$. odorata (IPCC, 2007; Wei et al. 2019): least suitable (0-0.2), low suitability (0.2-0.4), medium suitability (0.4-0.6), and high suitability (0.6-1).

\section{RESULTS AND DISCUSSION}

\section{Model performance}

Most ecological models are evaluated using statistical tests or indices or by field validation. As discussed, we evaluated model performance using the omissioncommission rate (Phillips and Dudk 2008), where the omission rate was calculated on both the training and test datasets (Figure 2; Anderson et al. 2003). We found good 
agreement between the omission rate for the training data and the predicted omission (Figure 2). The red line indicates the mean area, the black line indicates the predicted omission rate, and the light blue line indicates omission rates of the model training samples. The omission rate is calculated using both the presence records used for training and the test records (Anderson et al. 2003). The threshold-independent receiver operating characteristics (ROC) curve was also analyzed. ROC performance is represented by the area under curve (AUC; Figure 3). The ROC curve is a plot of sensitivity (the true positive fraction), i.e. the absence of omission error and the proportion of incorrectly predicted observed absences (1 specificity), or the false-positive fraction, i.e. commission error. The specificity is defined using the predicted area, rather than true commission. An AUC value of 0.50 indicates that the model is close to random and is a poor predictor, whereas a value of 1 indicates optimum model accuracy (Swets 1988). Model results should be rigorously evaluated, as a species' ecological niche covers a broader area than the geographical range of the species, and not all suitable areas are inhabited. Thus, using the maximum amount of information available for species distribution and the variables directly linked to species distribution is recommended. In this context, sites were surveyed for the presence of $H$. odorata and for predicted presence, to ground-truth the model. In the model, the lines of omission from the training data were close to predicted omission rates.

AUC values $<0.5$ indicate that a model is close to random and has poor predictive ability, whereas a value of 1 indicates perfect prediction (Swets 1988). We found an AUC value of 0.891 for our training dataset, indicating excellent predictive ability (Figure 3 ).

\section{Identification of suitable areas for $\boldsymbol{H}$. odorata}

MaxEnt produces a continuous raster with values from 0 to 1 , representing the lowest to highest habitat suitability, respectively (Yackulic et al. 2013; Xu et al. 2020) There are no rules to set thresholds to divide suitable from unsuitable habitat; rather, threshold determination depends on the user's objectives and varies between species and applications. MaxEnt provides threshold values based on a variety of statistical measures in the maxentResults.csv file. Some of the most common threshold determination methods include using a minimum training presence logistic threshold, a $10^{\text {th }}$ percentile training presence logistic threshold, and an equal training sensitivity and specificity logistic threshold (Phillips et al. 2006). We selected a $10^{\text {th }}$ percentile training presence logistic threshold (Kamyo and Asanok 2020). This threshold was applied using the average of all runs performed to reclassify the averaged model results to match the threshold values in Arc GIS. Thus, our final map had four classifications (Figure 4). Of the total study area (12,044.76 $\left.\mathrm{km}^{2}\right), 9.03 \%\left(1,087.90 \mathrm{~km}^{2}\right)$ was classified as highly suitably for $H$. odorata, $19.61 \%\left(2,362.22 \mathrm{~km}^{2}\right)$ was moderately suitable, $31.34 \% \quad\left(3,774.91 \mathrm{~km}^{2}\right)$ had low suitability, and $40.02 \%\left(4,819.73 \mathrm{~km}^{2}\right)$ was classified as least suitable. Previous studies of $H$. odorata have reported its habitat as riparian and low-relief areas in tropical forests (Bunyavejchewin et al. 2003). Our model indicated that the low-lying areas of Nakhon Sawan, Ang Thong, Phra Nakhon Si Ayutthaya, Pathum Thani, Nonthaburi, and Bangkok contained areas with the greatest probabilities of occurrence of $H$. odorata, whereas moderate probability areas were located in Lop Buri, Sing Buri, and Samut Prakan.

Table 2. Correlation coefficients between 19 bioclimatic variables obtained from WorldClim for the study area. Asterisks indicate a correlation coefficient $>0.90$. Bioclimatic variables are described in Table 1

\begin{tabular}{|c|c|c|c|c|c|c|c|c|c|c|c|c|c|c|c|c|c|c|c|}
\hline & $\underset{\overline{0}}{\bar{a}}$ & $\underset{0}{\stackrel{0}{0}}$ & $\stackrel{0}{0}$ & $\underset{\Xi}{\stackrel{\Xi}{0}}$ & $\stackrel{2}{0}$ & $\underset{\overbrace{}}{\varrho}$ & $\stackrel{\hat{0}}{\underline{0}}$ & $\stackrel{\infty}{\varrho}$ & $\stackrel{\hat{\theta}}{\underline{\theta}}$ & $\stackrel{0}{\frac{0}{0}}$ & $\underset{\overline{0}}{\overline{0}}$ & $\stackrel{\mathfrak{O}}{0}$ & $\frac{n}{0}$ & $\underset{0}{\stackrel{D}{0}}$ & $\frac{10}{0}$ & $\frac{0}{0}$ & $\frac{a}{0}$ & $\stackrel{\infty}{0}$ & $\stackrel{0}{0}$ \\
\hline$\overline{\mathrm{BIO} 1}$ & 1 & 0.27 & -0.4 & 0.39 & 0.28 & -0.32 & 0.3 & 0.12 & -0.36 & 0.39 & -0.28 & -0.43 & -0.29 & 0.14 & 0.15 & -0.31 & -0.17 & -0.24 & -0.32 \\
\hline $\mathrm{BIO} 2$ & & 1 & -0.86 & $0.95^{*}$ & $0.99 *$ & -0.97 & $0.99^{*}$ & 0.28 & -0.7 & $0.96^{*}$ & -0.93 & -0.9 & -0.99 & -0.65 & -0.61 & -0.97 & -0.73 & -0.67 & -0.95 \\
\hline BIO3 & & & 1 & -0.93 & -0.91 & $0.92 *$ & -0.92 & -0.28 & 0.82 & -0.9 & 0.9 & 0.83 & 0.88 & 0.61 & 0.5 & 0.89 & 0.71 & 0.57 & 0.9 \\
\hline BIO4 & & & & 1 & 0.95 & -0.99 & $0.98 *$ & 0.24 & -0.87 & $0.97 *$ & -0.98 & -0.94 & -0.97 & -0.57 & -0.46 & -0.97 & -0.77 & -0.66 & -0.96 \\
\hline BIO5 & & & & & 1 & -0.96 & $0.99 *$ & 0.3 & -0.72 & $0.96 *$ & -0.93 & -0.87 & -0.98 & -0.69 & -0.65 & -0.97 & -0.73 & -0.65 & -0.95 \\
\hline BIO6 & & & & & & 1 & -0.99 & -0.24 & 0.85 & -0.96 & $0.98 *$ & 0.92 & $0.98 *$ & 0.63 & 0.5 & $0.98 *$ & 0.8 & 0.66 & $0.97 *$ \\
\hline BIO7 & & & & & & & 1 & 0.27 & -0.78 & $0.97 *$ & -0.96 & -0.91 & -0.99 & -0.67 & -0.59 & -0.98 & -0.77 & -0.66 & -0.96 \\
\hline BIO8 & & & & & & & & 1 & -0.15 & 0.18 & -0.29 & -0.11 & -0.29 & -0.11 & -0.49 & -0.26 & 0 & -0.13 & -0.29 \\
\hline BIO9 & & & & & & & & & 1 & -0.75 & 0.89 & 0.79 & 0.76 & 0.44 & 0.24 & 0.8 & 0.71 & 0.59 & 0.81 \\
\hline BIO10 & & & & & & & & & & 1 & -0.92 & -0.94 & -0.96 & -0.55 & -0.46 & -0.96 & -0.73 & -0.61 & -0.93 \\
\hline BIO11 & & & & & & & & & & & 1 & 0.89 & $0.95 *$ & 0.59 & 0.51 & $0.96 *$ & 0.76 & 0.65 & $0.94 *$ \\
\hline BIO12 & & & & & & & & & & & & 1 & $0.92 *$ & 0.4 & 0.25 & $0.94 *$ & 0.72 & 0.66 & 0.9 \\
\hline BIO13 & & & & & & & & & & & & & 1 & 0.62 & 0.57 & $0.99 *$ & 0.74 & 0.7 & $0.95 *$ \\
\hline BIO14 & & & & & & & & & & & & & & 1 & 0.6 & 0.57 & 0.77 & 0.42 & 0.69 \\
\hline BIO15 & & & & & & & & & & & & & & & 1 & 0.55 & 0.2 & 0.33 & 0.47 \\
\hline BIO16 & & & & & & & & & & & & & & & & 1 & 0.71 & 0.7 & $0.94 *$ \\
\hline BIO17 & & & & & & & & & & & & & & & & & 1 & 0.59 & 0.86 \\
\hline BIO18 & & & & & & & & & & & & & & & & & & 1 & 0.67 \\
\hline BIO19 & & & & & & & & & & & & & & & & & & & 1 \\
\hline
\end{tabular}




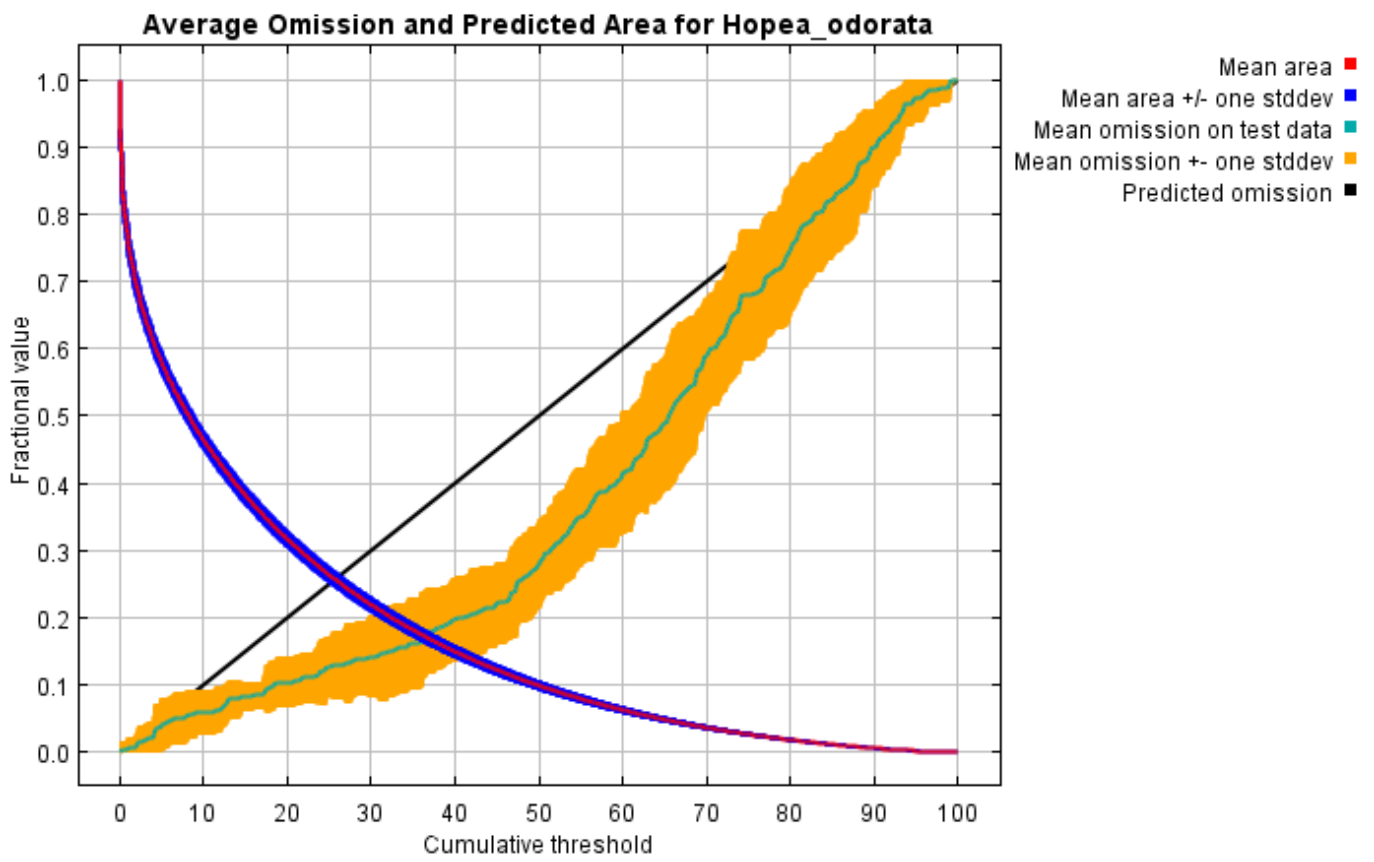

Figure 2. Omission rates versus predicted area for a MaxEnt model of predicted habitat suitability for Hopea odorata

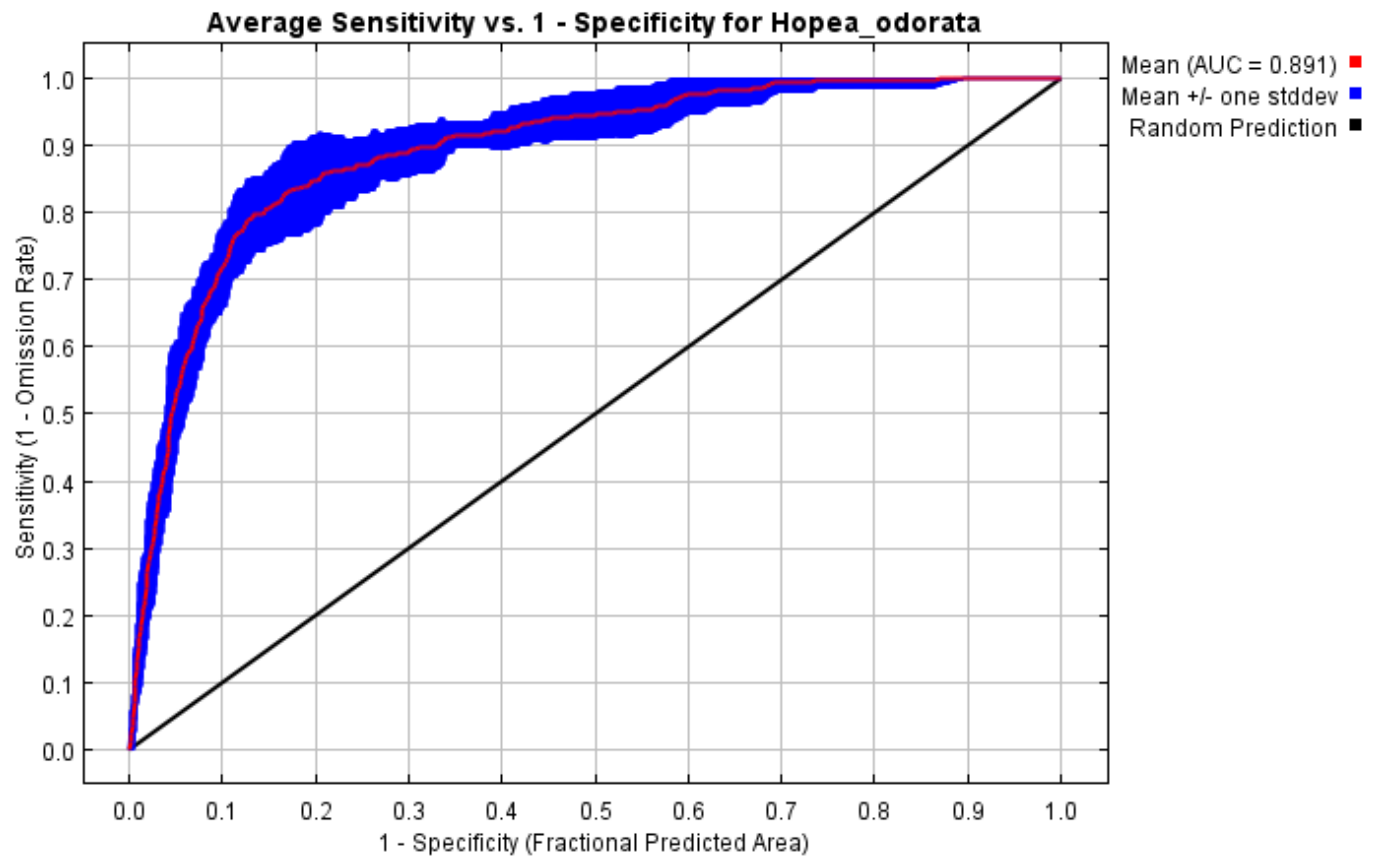

Figure 3. Results of area under the receiver operating characteristics curve (ROC-AUC) analyses for a MaxEnt model of habitat suitability for Hopea odorata 


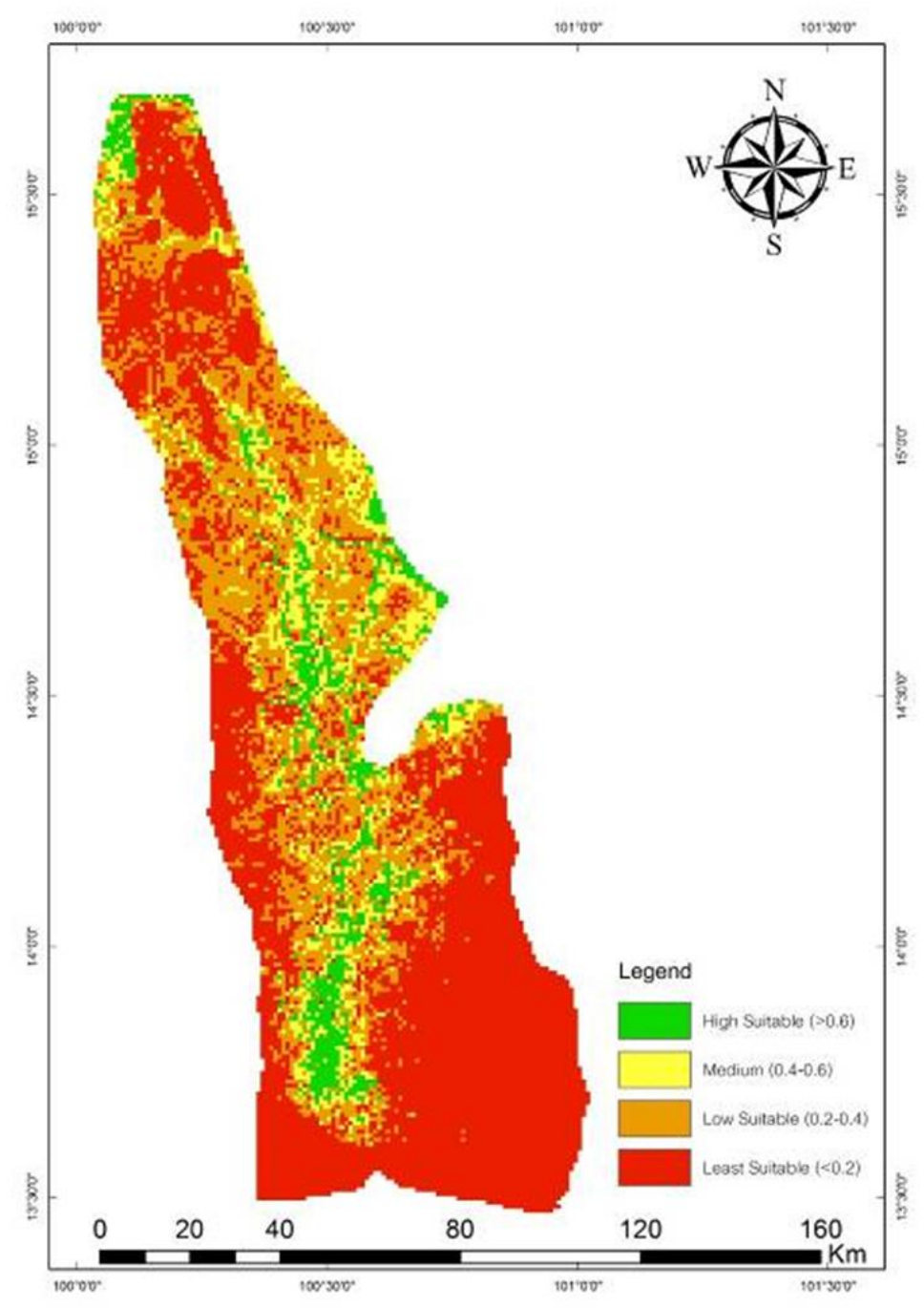

Figure 4. MaxEnt predicted habitat suitability within the study area for Hopea odorata

\section{Correlations of environmental factors}

Climatic factors set the broad limits to plant species distributions at the regional to global level (Shimwell et al. 1982; Woodward 1987; Prentice 1992; Taylor and Hamilton 1994). The climate variables included in this study and their relative contributions to model predictions are shown in Figure 5. Elevation was one of the most important environmental variables considered, with the greatest gain upon inclusion, and it represented $30 \%$ of the model's explanatory power when used in isolation. Annual precipitation caused the largest decrease in gain when omitted from the model. Minimum temperature contributed to the lowest gain when included in the model. Therefore, precipitation has important implications for the distribution and spread of $H$. odorata. In field surveys, this species was most often observed along streams and in flooded areas.

\section{Management implications}

Spatial data allow for the interpretation of species distributions, threats, and habitat requirements. The conservation status of a species is generally assessed by synthesizing information on known populations, changes in historical range, and evidence of vulnerability or threats to its required habitats. Maps using features such as natural regions or physiographic areas are typically the best format for presenting and understanding tree distribution data. SDMs allow for understanding species-habitat relationships by combining precise location data with microclimate, topographical, and edaphic factors. For threatened taxa, SDMs are vital to understanding the influence of biotic and abiotic factors in distribution patterns. The SDM presented here for $H$. odorata identifies potential areas along the Chao Phraya for the reforestation and conservation of this important species, both of which could act to reverse the observed decline in its natural populations. From a socioecological perspective, awareness of the importance of $H$. odorata in riparian systems is low, which is detrimental to conservation efforts. Increasing awareness of the ecological role of this species is crucial, and we hope that identifying areas with high suitability for its conservation will assist with future management efforts. 


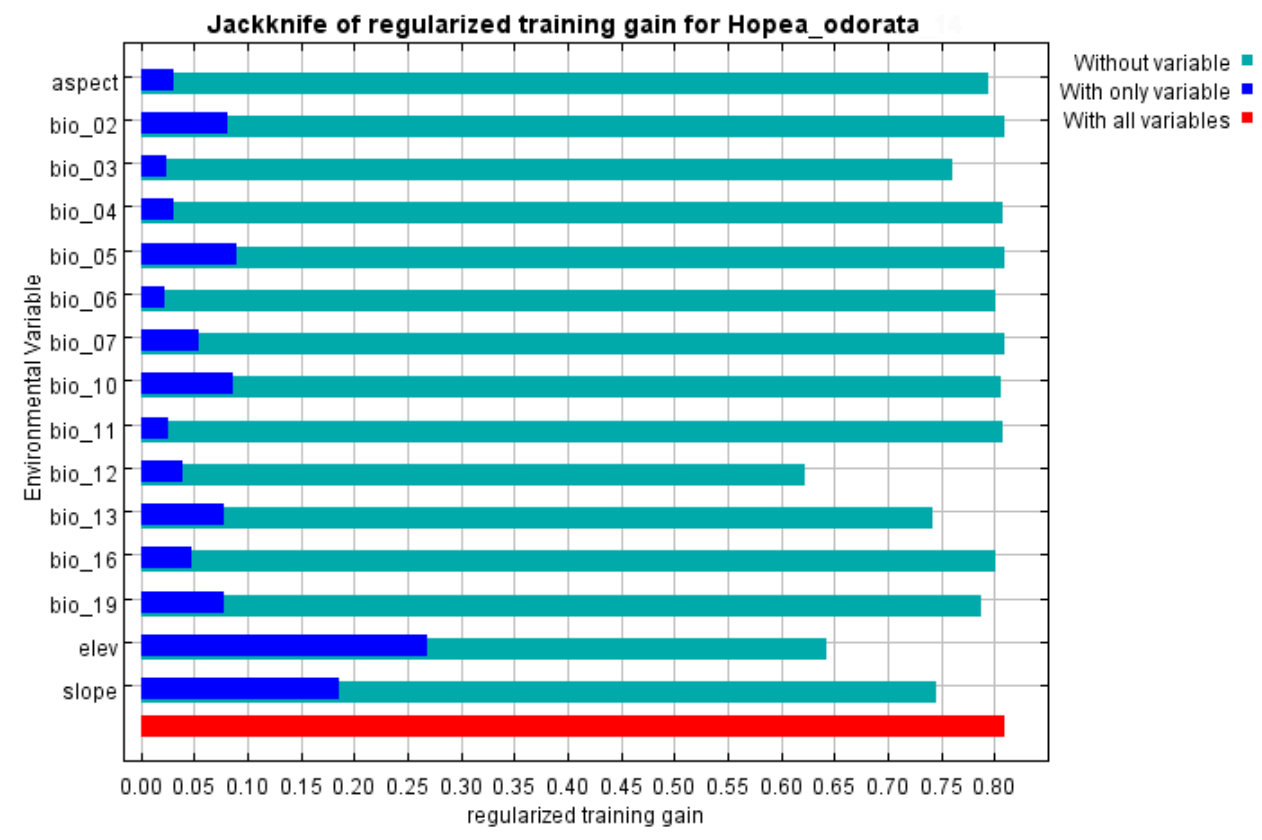

Figure 5. Jackknife estimates of relative variable contributions to training gain for Hopea odorata, obtained using MaxEnt

In conclusion, we used MaxEnt to predict the habitat distribution pattern of a dominant tree species using occurrence records and salient environmental variables. We identified $9 \%$ of the total study area as being suitable for $H$. odorata. Our habitat distribution map can assist in understanding the potential distribution of this species, particularly by highlighting high probability areas, and it provides a tool for land management in and around existing $H$. odorata populations. Furthermore, our SDM can be used to assist in locating new populations by identifying priority survey sites, and in the design of future conservation priority or resource management zones with an emphasis on the ecological boundaries for this species. As well, our map can be used to identify high-priority restoration sites. The approach described here is applicable to predicting suitable habitat for other threatened or endangered species that are limited by small sample sizes, and as we have shown, SDMs are powerful tools for biodiversity planning, monitoring, and management.

\section{ACKNOWLEDGEMENTS}

This research was made possible through the assistance of students from the Department of Agroforestry, Phrae Campus, Maejo University, Chiang Mai, Thailand. We thank the reforestation institute of PTT Public Company Limited for allowing us to conduct this study and for providing funding support (PTT-59-001).

\section{REFERENCES}

Abdelaal M, Fois M, Fenu G, Bacchetta G. 2019. Using MaxEnt modeling to predict the potential distribution of the endemic plant Rosa arabica Crép. in Egypt. Ecol Inf 50: 68-75.

Amici V, Marcantonio M, La Porta N, Rocchini D. 2017. A multitemporal approach in MaxEnt modelling: a new frontier for land use/land cover change detection. Ecol Inf 40: 40-49.

Anderson RP, Lew D, Peterson AT. 2003. Evaluating predictive models of species distributions: criteria for selecting optimal models. Ecol Model 162: 211-232.

Asanok L, Kamyo T, Norsaengsri M, Salinla-um P, Rodrungruang K, Karnasuta N, Navakam S, Pattanakiat S, Marod D, Duengkae P, Kutintara U. 2017. Vegetation community and factors that affect the woody species composition of riparian forests growing in an urbanizing landscape along the Chao Phraya River, central Thailand. Urban For Urban Greening 28: 138-149.

Ashton P, Kettle CJ. 2012. Dipterocarp biology as a window to the understanding of tropical forest structure: where are we looking now?. Biotropica 44 (5): 575-576.

Brito J, Acosta A, lvares F, Cuzin F. 2009. Biogeography and conservation of taxa from remote regions: an application of ecological-niche based models and GIS to North-African Canids. Biol Conserv 142 (12): 3020-3029.

Bunyavejchewin S, LaFrankie JV, Baker PJ, Kanzaki M, Ashton PS, Yamakura T. 2003. Spatial distribution patterns of the dominant canopy dipterocarp species in a seasonal dry evergreen forest in western Thailand. For Ecol Manag 175: 87-101.

Dormann F, McPherson CM, Araujo JB, Bivand M, Bolliger R, Carl J, Davies GG, Hirzel R, Jetz A, Daniel KW, Kuhn W, Ohlemuller I, Peres-Neto RR, Reineking P, Schroder B, Schurr F, Wilson R. 2007. Methods to account for spatial autocorrelation in the analysis of species distributional data: a review. Ecography 30 (5): 609-628.

Elith J, Kearney M, Phillips S. 2010. The art of modelling range-shifting species. Methods Ecol Evol 1: 330-342.

Elith J, Phillips S J, Hastie T, Dudík M, Chee YN, Yates CJ. 2011. A statistical explanation of MaxEnt for ecologists. Divers Distrib 17: 43-57. 
Fielding AH, Bell JF. 2007. A review of methods for assessment of prediction errors in conservation presence/absence models. Environ Conserv 24: 38-49.

Fois M, Cuena-Lombraña A, Fenu G, Cogoni D, Bacchetta G. 2016. The reliability of conservation status assessments at regional level: past, present and future perspectives on Gentiana lutea L. ssp. lutea in Sardinia. J Nat Conserv 33: 1-9. DOI: 10.1016/j.jnc.2016.06.001.

Franklin J. 2009. Mapping Species Distributions: Spatial Inference and Prediction. Cambridge University Press, Cambridge, UK.

Gale EL, Saunders MA. 2014. The 2014 Thailand Flood: Climate Causes and Return Periods. Department of Space and Climate Physics, University College London, London.

Guisan A, Zimmermann N. 2000. Predictive habitat distribution models in ecology. Ecol Model 135 (2-3): 147-186.

Hijmans RJ, Cameron SE, Parra JL, Jones PG, Jarvis A. 2005. A very high resolution interpolated climate surface for global land areas. Int J Climatol 25: 1965-2198.

Hossain MM, Kabir MSH, Chowdhury TA, Hasanat A, Chakrabarty N. 2015. Anthelmintic effects of different extracts of Hopea odorata leaves on Tubifex tubifex worm using in vitro method and their condensed tannin content. $\mathrm{Br}$ J Pharm Res 8 (3): 1-7. DOI 10.9734/BJPR/2015/19064.

Hydro and Agro Informatics Institute. 2012. Implementation of data collection and analysis of data development project of 25 watersheds: the Chao Phraya watershed. ASDECON Corporation, Bangkok.

IPCC. 2007. Contribution of Working Groups I, II, III to the Fourth Assessment Report of the Intergovernmental Panel on Climate Change. Climate Change 2007, Synthesis Report, Geneva.

Jaryan V, Datta A, Uniyal SK, Kumar A, Gupta RC, Singh RD. 2013. Modelling potential distribution of Sapium sebiferum- an invasive tree species in Western Himalaya. Curr Sci 105 (9): 1282-1288.

Kamyo T, Asanok L. 2020. Modeling habitat suitability of Dipterocarpus alatus (Dipterocarpaceae) using MaxEnt along the Chao Phraya River in Central Thailand. For Sci Technol 16 (1): 1-7. DOI 10.1080/21580103.2019.1687108.

Khanum R, Mumtaz AS, Kumar S. 2013. Predicting impacts of climate change on medicinal asclepiads of Pakistan using Maxent modeling. Acta Oecol 49: 23-31.

Koch R, Almeida-Cortez JS, Kleinschmit B. 2017. Revealing areas of high nature conservation importance in a seasonally dry tropical forest in Brazil: Combination of modelled plant diversity hot spots and threat patterns. J. Nat. Conserv. 35, 24-39.

Lamb D. 2010. Regreening the Bare Hills: Tropical Forest Restoration in the Asia-Pacific Region. Springer Science and Business Media.

Montagnini F, Jordan CF. 2005. Tropical Forest Ecology. Springer, Berlin.

Narong N, Sobon K. 2014. Review of biological and silvicultural characteristics of timber trees planted in Cambodia. http://www.irdfa.org/wp-content/uploads/2017/11/Review-ofbiological-and-silviculturalcharacteristics-of-timber-trees-planted-inCambodia.pdf.

Orwa C, Mutua A, Kindt R, Jamnadass R, Anthony S. 2009. Agroforestree database: a tree reference and selection guide version 4.0. World Agroforestry Centre, Kenya.

Phillips S, Dudk M. 2008. Modeling of species distributions with Maxent: new extensions and a comprehensive evaluation. Ecography 31 (2): $161-175$.
Phillips S, Anderson RR, Schapire R. 2006. Maximum entropy modeling of species geographic distributions. Ecol Model 190 (3-4): 231-259.

Prentice IC. 1992. Climate change and long-term vegetation dynamics. In: Glenn DC, Peet RK, Veblen TT (eds). Plant Succession: Theory and Prediction. Chapman and Hall, London.

Safaei M, Tarkesh M, Bashari H, Bassiri M. 2018. Modeling potential habitat of Astragalus verus Olivier for conservation decisions: a comparison of three correlative models. Flora 242: 61-69.

Sakai A, Visaratana T, Vacharangkura T, Thai-ngam R, Tanaka N, Ishizuka M, Nakamura S. 2009. Effect of species and spacing of fastgrowing nurse trees on growth of an indigenous tree, Hopea odorata Roxb., in northeast Thailand. For Ecol Manag 257: 644-652.

Satiraphan M, Pamonsinlapatham P, Sotanaphun U, Sittisombut C, Raynaud F, Garbay C, Michel S, Cachet X. 2012. Lupane triterpenes from the leaves of the tropical rain forest tree Hopea odorata Roxb. and their cytotoxic activities. Biochem Syst Ecol 44: 407-412.

Scheldeman X, Zonneveld M. 2010. Training Manual on Spatial Analysis of Plant Diversity and Distribution. Biodiversity International, Rome.

Shimwell D, Box E, Lieth H. 1982. Macroclimate and plant forms: an introduction to predictive modeling in phytogeography. J Appl Ecol 19 (3): 993-998.

Swanti S, Kusum A, Dhruval B, Rajkanti K. 2018. Modeling habitat suitability of Perilla frutescens with MaxEnt in Uttarakhand-A conservation approach. J Appl Res Med Aromat Plants 10: 99-105.

Swets JA. 1988. Measuring the accuracy of diagnostic systems. Science 240: 1285-1293.

Taylor D, Hamilton A. 1994. Impact of climate change on tropical forests in Africa: Implications for protected area planning management. In: Pernetta JG, Leemans R, Endler HD (eds.). Impacts of Climate Change on Ecosystems and Species: Implications for protected areas. IUCN, Gland, Switzerland.

Warren DL, Glor RE, Turelli M. 2008. Environmental niche equivalency versus conservatism: quantitative approaches to niche evolution. Evolution 62 (11): 2868-2883.

Wei J, Kai H, Yunyun L, Jiufeng W. 2020. Predicting the potential distribution of the vine mealybug, Planococcus ficus under climate change by MaxEnt. Crop Prot 137: 105268. DOI: 10.1016/j.cropro.2020.105268.

Woodward FI. 1987. Climate and Plant Distribution. Cambridge University Press, Cambridge.

Xu N, Meng F, Zhou G, Li Y, Wang B, Lu N. 2020. Assessing the suitable cultivation areas for Scutellaria baicalensis in China using the Maxent model and multiple linear regression. Biochem Syst Ecol 90: 104052. DOI: 10.1016/j.bse.2020.104052.

Yackulic CB, Chandler R, Zipkin EF, Royle JA, Nichols JD, Campbell Grant EH, Veran S. 2013. Presence-only modelling using MAXENT: when can we trust the inferences? Methods Ecol Evol 4: 236-243.

Zimmer HC, Le TH, Lo D, Baynes J, Nichols JD. 2018. Why do farmers still grow corn on steep slopes in Northwest Vietnam?. Agrofor Syst 92, 1721-1735.

Zheng X, Kao S, Chen Z, Menviel L, Chen H, Du Y, Wan S, Yan H, Liu Z, Zheng L, Wang S, Li D, Zhang X. 2016. Deepwater circulation variation in the South ChinaSea since the Last Glacial Maximum. Geophys Res Lett 43: 1-10. DOI: 10.1002/2016GL070342.

Zhu G P, Gariepy T D, Haye T, Bu W J. 2017. Patterns of niche filling and expansion across the invaded ranges of Halyomorpha halys in North America and Europe. J Pest Sci 90: 1-13. 